\title{
Modeling of the Aerial Capacity through a Leontief Production Function: The Case of Tunisian Airports
}

\author{
Harizi Besma ${ }^{1, *}$, Harizi Riadh ${ }^{2}$ and M'raïhi Rafaa ${ }^{1}$ \\ ${ }^{1}$ University of Manouba and GEF2A Laboratory, Tunis University, Tunisia \\ ${ }^{2}$ University of Bisha, Community College, Department of Business Administration and University of \\ Tunis- GEF2A Laboratory, Tunisia
}

\begin{abstract}
Our objective is to model the airport capacity through a Leontief production function, which is based on the complementarity of the factors defining airport capacity. Results of our simulation for all Tunisian airports show that we can determine, especially, foreseeable future of the congestion, traffic processed by infrastructure, availability of infrastructures, the factors that block the circulation on the ground, and time measurements: delays, waiting time, and runway occupancy time. According to their capabilities (reduced, declared, optimal), three airports are identified. However, it is possible to avoid the extra costs experienced by the terminals and to optimize airports' capacity by making a reallocation of human resources and opting for a better exploitation of the existing infrastructures.
\end{abstract}

Keywords: Airport Capacity, Availability, Modeling, Leontief Production Function, Tunisian airports.

\section{INTRODUCTION}

The growth in demand for air transport is considerable ( $9 \%$ per year since 1950), the overall system of the Air Navigation has reached a degree of use close to the saturation, thus, causing many delays during the high demand periods; which caused a congestion difficult to quantify. The saturation essentially affects the tracks that constitute the critical interface between the airspace and the airport and which constitute at some airports the main bottlenecks. Now, these tracks host the landings and emerge the takeoffs depending on the direction of the prevailing winds and their availability. In addition, for safety measures, it is better to opt for the specialization of the tracks (landings or takeoffs) because the simultaneous management of the landing and of the takeoff is difficult (Alvarez et al., 2002).

For speed and air safety reasons, the runways intended for the landing are considered more important than those intended for the takeoff. They require a good management of the scheduling of the landings of the aircrafts, since this management depends on the complexity of the air transport system. The aircraft landing problem is, since a long time, a complex and a difficult one when it comes to controlling the air traffic. Consequently, many theoretical works have been developed around this topic to present realistic and optimal solutions.

*Address correspondence to this author at the University of Manouba, High School of Business, Tunis 2010, Tunisia; Tel: +21658479963; Fax: +21671588514; E-mail: harizibesma@yahoo.fr
Today, the system must guarantee a safe, secured, regular and sustainable functioning, and the airport capacity must be optimized. (International Civil Aviation Organization [ICAO], 2007).

The air traffic management relies on constraints, prerequisites and more generally on four series of quantifiable objectives: (i) the security (wake vortices between planes, safety measures, security, and fire), (ii) the flights regularity (minimizing the delays, improving the quality of services), (iii) the respect of the environment (mastering the noise impacts and the polluting emissions) and (iv) the technical and economic efficiency (Harizi et al., 2013; Direction Générale de l'Aviation Civile, service technique de l'aviation civile, 2005). On the other hand, as for any other mode of transport, the service of an air transport system is defined by the capacity, provided by this system during a specified period and under given conditions. (Janic, 2007; European Union [EU], 2010).

The airport capacity is defined by the flows of the airplanes or by the passengers that the platform is able to flow out to the users in satisfactory conditions. It is, therefore, important to study the airport capacity and that is for at least two purposes: (1) to objectively measure the capacity of the airport system components to manage the aircraft movement forecasts and the passengers flows. (2) to estimate the magnitude of the delays in the system with a variable demand (Ashford and Wright, 1992).

We also believe that the study of the capacity serves to determine the reserves of the capacity and the deadline of saturation. Indeed, the comparison 
between the evolution of the capacity and the traffic prediction allows programming the future investments in an airport. Furthermore, we must seek to control and to regulate the capacity according to the managers needs to deal with the contingencies and to optimize the level of the capacity (Idrissi and LI Chu, 2005; Dobruszkes, 2009).

The study of the capacity necessitates taking into account various factors which influence it. Generally, the capacity depends on the minimum time needed for the processing of the elements that go into one of the systems (Venkatakrishnan et al., 1993) and on the frequency of appearance in this system (Figure 1).

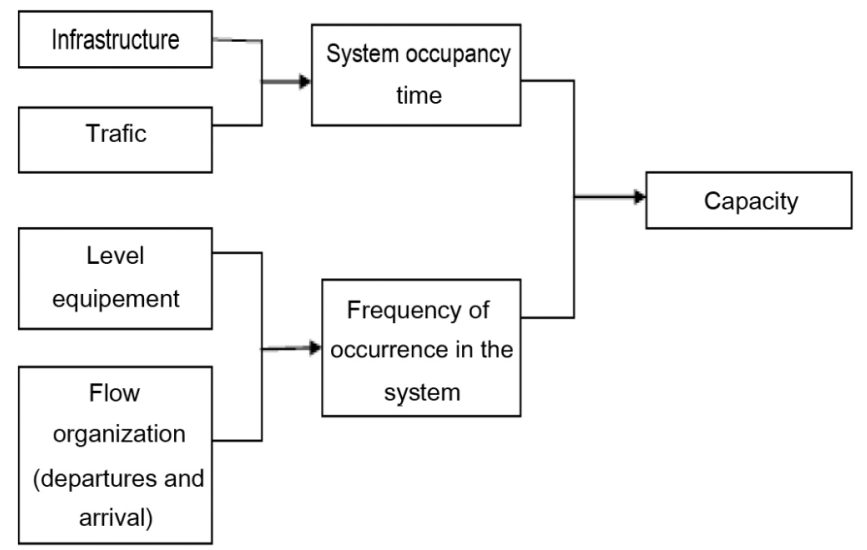

Figure 1: Factors and mechanisms of the airport capacity.

Source: elaborated by the author.

The restrained dimensions of the aerial system and the growing volume of the air traffic increase the level of the congestion both in the air and in the soil; therefore, an increase in deadlines will take place (Eugene and Gilbo, 1993). More generally, one can affirm that the capacity depends on the minimum time needed for the treatment of the elements that go into one of the systems and on the frequency of appearance in this system. This time and this frequency depend upon what we call the technical components having a direct impact on the technical capacity: the runways, the taxiways and the parking areas, which constitute the factors on which a planner ${ }^{1}$ can act. (Bauerle et al., (2007). In fact, the modeling of the aerial capacity is the fact of linking the traffic prediction to the forecasting of the infrastructure requirements (Cristobal, 2003). It is therefore crucial to find a more comprehensive approach to capacity

\footnotetext{
${ }^{1}$ The "planner" can be defined here by the legal or the natural person who establishes the infrastructures and the activity planning and activity, as well as the necessary documents, in view of the strategy of all the concerned actors.
}

concerned with the entire airport system. The modeling must ensure the calculation of the capacity of each airport and the determination of their different extra costs.

We believe that modeling is inscribed in a multiple framework. On the one hand, it is a question of offering technical advice for the airports to overcome the problem of congestion, and on the contrary, the study of the capacity is also a tool for planning, for management and for the control of airports investment opportunities both in the medium and the long term.

It is, thus, that this paper seeks to model, calculate and simulate the airport capacity in order to subsequently classify the airports in an ascending order of capacity. The method will also lead to the detection of failures at the airports and to forward useful recommendations for decision-making. The article is organized as follows. In Section 2, we present the modeling of airport capacity. The third section constitutes an application of the model about the Tunisian airports. The results are presented, interpreted and discussed. The final section will conclude.

\section{MODELING THE ECONOMIC CAPACITY}

Generally speaking, a production function summarizes all the technological and organizational characteristics of the firm (Varian, 2011). Regarding the transport, its production requires capital, labor, inputs and organization, but with unique features and a great diversity depending on the modes. (Michel and Prud'homme, 2007).

The production function must be described by a relatively reasonable number of parameters; its shape admits some properties such as the elasticity of substitution between each pair of inputs. We will model the airport capacity with the help of a production function while specifying its nature. Unlike the production function of Cobb Douglass and CES (Constant Elasticity of Substitution) type, the Leontief production function type is the most suitable for our study. This choice is motivated by the fact that this function consists of a set of interrelated factors, which is the case of the airport capacity.

\subsection{The Production Function Parameters}

The technical parameters used in our model are measurable, and they allow assessing the level of capacity: the number of tracks $(n)$, the number of the 
air controllers $(c)$ and the number of the parking positions $(h)$ :

\subsubsection{Number of Tracks (n)}

A landing runway or a takeoff runway of an airport is a strip of land on which the airplanes can land or take off. The tracks can be made of concrete, asphalt, grass or just land. Most of the tracks are used both for the landing and for the takeoff. This presupposes an organization and a seamless synchronization of aircraft movements. When the airport receives a heavy traffic, it is common to build the tracks in groups into two parallel tracks in order to separate the takeoff movements from the movements per minute and a half, sometimes a little more, by taking into account the period for dissipating the greatest part of the wake turbulence (De Neufville, 2005; ICAO, 2007). Technically, the tracks are oriented in the direction of prevailing winds, so as to make the planes take advantage of the aerial currents facilitating the take-off and improving the braking. During the landing, the airplanes are always facing the wind. In case of bad meteorological conditions (heavy rain, snow, freezing rain, low visibility, gusting winds), the capacity of airports can radically vary and it becomes much reduced. The disturbances engendered by this type of situations are very penalizing both for the users and for the air services under stress that are not completely satisfied. The effects of the meteorological conditions on the capacity specified at the arrival of the airplanes may be unfavorable, as shown in Figure 2. Thus, the weather is undoubtedly the most common category of threats to all aspects of aviation (Raffarin, 2002;

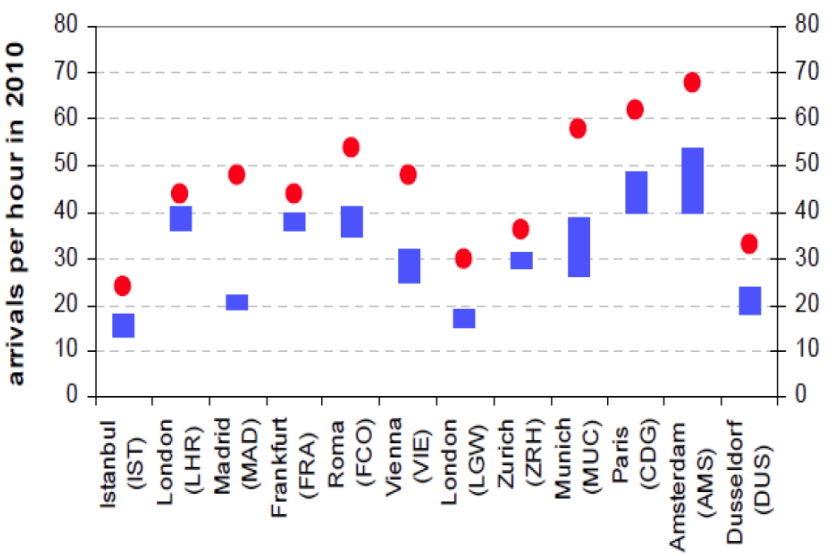

Spread between the 50 th and the 20 th percentile of weather related ATPM capacity reductions

- Peak declared capacity for arrivals

Figure 2: Reduction of arrival runways capacity in terms of adverse weather conditions.

Source: Adapted from EUROCONTROL (2013).
European Organisation for the Safety of Air Navigation [EUROCONTROL], 2013).

\subsubsection{Number of the air Controllers (c)}

The air traffic controllers are the people who are responsible for the control, security and air traffic management. To maintain a safe separation of the aircraft on the surface of the airport, the air traffic controllers deliver the verbal authorizations to the pilots of the plane at the arrival, the departure, and at the sequences of the passages of the track (Eggert et al., 2006). Indeed, their fundamental role is to take better advantage of the installed airport traffic capacity to manage traffic flows by ensuring the safety of aircrafts. These controllers help to streamline and organize the movement of aircrafts in the sky. They remain the least involved in the occurrence of air accidents during the period from 1950 to 2008 (Harizi et al., 2013).

\subsubsection{Number of the Parking Positions (h)}

The number of parking places (or of necessary parking) for each airport can be determined by a predictive method of utilization of the areas. This method comprises the following steps of providing the traffic with expected regular line, choosing the type of plane for each line, and identifying the possible timetables and the number of aircrafts that are simultaneously present on the tarmac.

It is then necessary to assess the consequences of the delays that can never be excluded and the failures that can immobilize an aircraft on station. This consideration can lead to allow an additional parking position.

\subsection{Objective Function and Constraints}

Our ambition is to model the airport capacity with a production function of a Leontief type since the production and the airport capacity simulation factors are complementary. The function that we propose takes the following form: (1)

$Y=\min (P / w, Q / v, R / r) \equiv Y=\min \left(y_{1}, y_{2}, y_{3}\right)$

To minimize this production function, three types of constraints at least must be considered: the constraint of runways availability, that of pilot availability and the one of the parking availability.

\subsubsection{Runways Availability Constraint}

The aforementioned function defines the track availability in hours, taking into account the maximum time of the airplanes occupancy. The following function defines it: (2) 
$y_{1}=P / W$

The $y_{1}$ values are calculated by the ratio between the availability of runways per hour $(P)$ and the average time of occupancy of a runway by an airplane $(w)$. Thus, $P$ represents the availability of $n$ airport runways in hours as follows: (3)

$P=n \times T$

Where $T$ designates the time interval retained in this work (an 8 am workstation), $w$ denotes the occupation time of a runway by a single aircraft.

According to the data from the Office for Civil Aviation and Airports in Tunisia [OCAA], every airplane occupies a runway for 19 minutes (on average), so, $w$ $=19 / 60=0.3 \mathrm{~h}$.

\subsubsection{The Constraint of Availability of Pilots}

This constraint is interested in the human factor, it defines the availability of the land pilots, taking into account the time needed to take-off or land an airplane. It is defined by the following function: (4)

$y_{2}=Q / V$

Where $y_{2}$ denotes the ratio of the availability of piloting time in hours $(Q)$ and the time required for the take-off and the landing of an airplane (v). The following relationship defines $Q$ : (5)

$Q=s \times C$

An expression in which $s$ means the average working time for an air traffic controller, $c$ shows the number of air traffic controllers and $v$ represents the time required for the landing or the take-off of an airplane. Data from different Tunisian airports show that the landing of an aircraft takes place in an interval of three to four minutes, and that its take-off requires four to five minutes. Thus, the average time of the landing and of the take-off will be equal to $(3.5+4.5) / 2$ $=4$ minutes. $\mathrm{v}=4 / 60=0.07 \mathrm{~h}$.

\subsubsection{Parking Availability Constraint}

This constraint is the maximum number of airplanes insured in 8 hours of work (6).

$y_{3}=R / r$

Mathematically, the $y_{3}$ values are calculated by the ratio between the availability of parking areas in hours $(R)$ and the average residence time of an airplane on a parking $(r)$, its expression is: $(7)$
$R=h \times d$

Where $h$ represents the number of parking positions; $d$ represents the number of work hours per position (8 hours).

In the present work, the average residence time of a plane in a parking is estimated over a period equal to one week of work.

\section{RESULTS AND DISCUSSION}

The modeling of airport capacity under constraints allows determining the primary factors of extra costs. Our method allows to classify the Tunisian airports according to their capacities and to discuss the possible optimization solutions.

Data and results are summarized in the Tables 1 and 2. Figure 3 reflects the classification of the studied airports. The designation identifies three types of airports: three airports of optimum capacity (TunisCarthage, Monastir H Bourguiba, and Tozeur), two airports with a reduced capacity (Djerba Zarzis and Gafsa) and three other ones with a declared capacity ${ }^{2}$ (Sfax, Tabarka and Gabes). Noting that the airports with announced capacity are characterized by a small and a seasonal traffic; practically, they annually host only a flow of passengers and of airplanes; which is almost at the level of their real capacities.

\subsection{Runways' Availability}

The results show that only three airports arrive to meet the constraint of Tracks' availability. These airports are (Tunis Carthage airport, Monastir $\mathrm{H}$ Bourguiba airport and Sfax airport). Indeed, the operating costs of the tracks, for these airports, respectively reach 53,53 and 27 .

The results show a particular importance of both Tunis Carthage airport and Monastir $\mathrm{H}$ Bourguiba airport. The recorded extra-costs are derived, at the same time, from the pilots-controllers and from the parking. The statistics also show the presence of, respectively, nine and eight air controllers during a working period of eight hours; however, two air controllers are sufficient to ensure the considered traffic: it is a problem of mismatch between the supply

\footnotetext{
${ }^{2}$ The "declared capacity" represents the flow rate of the airplanes or of the passengers that the airport is able to accept all year long, taking into account the assembly of the elements of the airport chain as well as the external constraints.
} 
Table 1: Statistics and Results of Production Functions

\begin{tabular}{|c|c|c|c|c|c|c|c|c|}
\hline Airports & $\begin{array}{c}\mathrm{T} \\
\text { (hours) }\end{array}$ & $\mathbf{N}$ & $\begin{array}{c}\text { P } \\
\text { (hours) }\end{array}$ & $\begin{array}{c}\text { w } \\
\text { (hours) }\end{array}$ & $Y_{1}=P / w$ & $\begin{array}{c}\text { S } \\
\text { (hours) }\end{array}$ & c & $\begin{array}{c}Q \\
\text { (hours }\end{array}$ \\
\hline Tunis-Carthage & 8 & 2 & 16 & 0.3 & 53 & 6 & 9 & 54 \\
\hline $\begin{array}{c}\text { Monastir H- } \\
\text { Bourguiba }\end{array}$ & 8 & 2 & 16 & 0.3 & 53 & 6 & 8 & 48 \\
\hline Sfax & 8 & 1 & 8 & 0.3 & 27 & 6 & 5 & 30 \\
\hline Djerba- Zarzis & 8 & 1 & 8 & 0.3 & 27 & 6 & 4 & 24 \\
\hline Tozeur & 8 & 2 & 16 & 0.3 & 53 & 6 & 3 & 18 \\
\hline Tabarka & 8 & 2 & 16 & 0.3 & 53 & 6 & 2 & 12 \\
\hline Gafsa & 8 & 1 & 8 & 0.3 & 27 & 6 & 1 & 6 \\
\hline \multirow[t]{2}{*}{ Gabes } & 8 & 1 & 8 & 0.3 & 27 & 6 & 1 & 6 \\
\hline & $\begin{array}{c}\text { V } \\
\text { (hours) }\end{array}$ & $\begin{array}{c}Y_{2}=Q / \\
V\end{array}$ & H & $\begin{array}{c}\text { D } \\
\text { (hours) }\end{array}$ & $\mathbf{R}$ & $\mathbf{r}$ & $Y_{3}=R / r$ & $Y=\min \left(\frac{P}{w}, \frac{Q}{v}, \frac{R}{r}\right)$ \\
\hline Tunis-Carthage & 0.07 & 771 & 46 & 8 & 368 & 1.20 & 307 & 53 \\
\hline $\begin{array}{c}\text { Monastir H- } \\
\text { Bourguiba }\end{array}$ & 0.07 & 686 & 25 & 8 & 200 & 1.18 & 169 & 53 \\
\hline Sfax & 0.07 & 428 & 22 & 8 & 176 & 1.13 & 156 & 27 \\
\hline Djerba- Zarzis & 0.07 & 343 & 2 & 8 & 16 & 1.03 & 16 & 16 \\
\hline Tozeur & 0.07 & 257 & 6 & 8 & 48 & 1.12 & 43 & 43 \\
\hline Tabarka & 0.07 & 171 & 3 & 8 & 24 & 1.08 & 22 & 22 \\
\hline Gafsa & 0.07 & 86 & 2 & 8 & 16 & 1.16 & 14 & 14 \\
\hline Gabes & 0.07 & 86 & 3 & 8 & 24 & 1.22 & 20 & 20 \\
\hline
\end{tabular}

and the demand. Indeed, an overstaffing of aerial controllers engenders high costs of human resources and therefore an increase in the cost of the airport's functioning.

Table 2: Different Types of Tunisian Airports' Capacities

\begin{tabular}{|c|c|c|}
\hline $\begin{array}{c}\text { Airports of } \\
\text { optimum capacity }\end{array}$ & $\begin{array}{c}\text { Airports with a } \\
\text { declared capacity }\end{array}$ & $\begin{array}{c}\text { Airports with a } \\
\text { reduced capacity }\end{array}$ \\
\hline \hline Tunis Carthage & Sfax & Djerba Zarzis \\
\hline $\begin{array}{c}\text { Monastir } \\
\text { H-Bourguiba }\end{array}$ & Tabarka & Gafsa \\
\hline Tozeur & Gabes & \\
\hline
\end{tabular}

On the flip side, the balance onto these three airport infrastructures is established at the level of their constraints of availability of the runways. So, these airports a real exploitation achieve a real exploitation of their infrastructures, which explains the good organization and the perfect synchronization of the airplanes' movements.

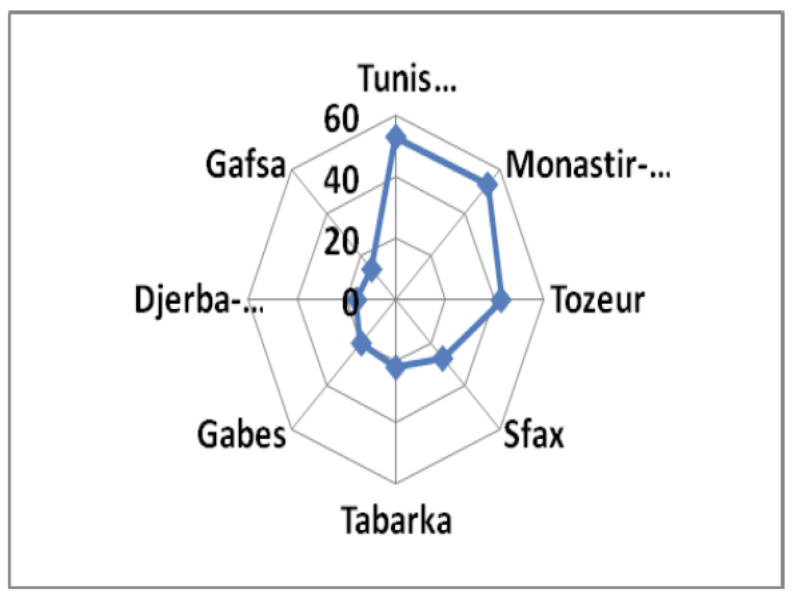

Figure 3: Extent of the capacity of Tunisian airports.

\subsection{The Availability of the Pilots Controllers}

No airport satisfies the constraint of the air controllers' availability. The airports of Tunis Carthage and Monastir $\mathrm{H}$ Bourguiba present the highest costs of the availability of the pilots controllers. They respectively reach the values 771 and 686 . Indeed, during 8 hours of work, the supposed number of pilots 
controllers is considerably higher than the optimum, which inflates the costs of human resources. So the pilots' assignment is not harmonized with the request: it is still a problem of inadequacy between supply and demand.

\subsection{The Availability of Parkings}

Only five airports reach their equilibriums onto the constraint of availability of parkings: Djerba, Tozeur, Tabarka, Gafsa and Gabes. For these airports, the additional costs derive from the availability of air controllers and the runways' availability. We note that most of these airports have more than one runway, so it is the wrong exploitation of the existing infrastructures which engenders these incremental operating costs.

These airports can do a good traffic's provision per regular line, a good choice of the airplane type for each line, a perfect determination of the possible schedules. Finally, these airports are the most capable at the level of mastery of delays and the airplanes' breakdowns on parking positions.

\section{CONCLUSION}

The modeling of the airport capacity using a Leontief production function has allowed ensuring optimization solutions of this capacity and so to remedy the airport congestion this capacity and so to remedy the airport congestion. Practically, each time that the demand exceeds the capacity, the managers try to solve the congestion by delaying few flights in order to facilitate the flow of the traffic and ensure a maximum utilization of the capacity. Therefore, the delays of takeoffs and of landings of airplanes are in particular due to the mismatch between supply and demand on the airport infrastructure.

However, using this modeling, a simulation is performed on the assembly of the Tunisian airports while permitting the determination of predictable schedules of congestion, the traffic processed by the infrastructure, and the measures of times (runways occupancy time, waiting times, and the delays).

Thus, the airports capacity is a vital datum both for managers as well as for airline companies. Its optimization would allow managing an optimum traffic, to ensure its fluidity, to satisfy the demands of the airline companies and to have flexibility in the management of air transport.

Empirically, the method allowed to classify the Tunisian airports according to their optimum capacity into three categories: three airports with optimum capacity (Tunis-Carthage, Monastir $\mathrm{H}$ Bourguiba, and Tozeur), two airports with reduced capacity (Djerba Zarzis, Gafsa) and three others with declared capacity (Sfax, Tabarka, Gabes). Most of these airports must make a reallocation of human resources and opt for a better exploitation of the existing infrastructures. They are thus incited using these results in an optimal way taking into account their production factors.

\section{REFERENCES}

Alvarez J., Creton, R., Galindou, L., Ponamale, L., Rodriguez, J. 2002. Techniques de l'ingénieur, CE1(C4452):1-17, ISSN 1763-6825.

Ashford, N., Wright, P.H. 1992. Airport engineering. New York: John Wiley, 3rd ed. https://doi.org/10.1002/9780470172896

Bauerle, N., Engelhard, O., Kolonko, M. 2007. "On the waiting time of arriving aircrafts and the capacity of airports with one or two runways". European Journal of Operational Research, 177 (2):1180-1196. https://doi.org/10.1016/j.ejor.2006.01.002

Cristobal, J. 2003. La prévision des trafics aéroportuaires par AENA AENA-Aeropuertos Espanoles y Navegacion Aérea Espagne, $16 \mathrm{p}$

De Neufville R. 2005. Le devenir des aéroports secondaires : bases d'un réseau parallèle de transport aérien ? Les Cahiers Scientifiques du Transport, $n^{\circ} 47$, pp. 11-38

Direction Générale de l'Aviation Civile, service technique de l'aviation civile, 2005. Détermination de la capacité d'un aéroport Manuel de référence pour la détermination de la capacité d'un aéroport, sous la direction de Cateloy, O. et Rodriguez, J., éds de l'Atelier de reprographie du STAC, France, 132 p.

Dobruszkes, F. 2009. Systèmes urbains, économie régionale, stratégies d'acteurs et desserte aérienne européenne : une analyse empirique. Les Cahiers Scientifiques du Transport, (56):9-36.

Eggert, J.R. Howes, B.R., Kuffner, M.P., Wilhelmsen, H., Bernays, J 2006. "Operation Evaluation of Runway Status Lights", lincoln laboratory journal, 16(1):123.

Eugene, P., Gilbo, 1993. "Airoport capacity: Representation, Estimation, Optimization". IEEE Transactions on control systems technology, 1(3):144-154. https://doi.org/10.1109/87.251882

European Organization for the Safety of Air Navigation (EUROCONTROL). 2013. Performance Review Commission. Performance Review Report. An assessment of Air Traffic Management in Europe during the calendar year 2013, PRR 2013, 227 p.

European Union. 2010. Commission Regulation (No 691/2010 of 29 July 2010) laying down a performance scheme for air navigation services and network functions and amending Regulation (EC) No 2096/2005 laying down common requirements for the provision of air navigation services Text with EEA relevance. Official Journal of the European Union, pp. 1-22.

Harizi, R., Belhaiza, M.A., Harizi, B. 2013. "A Cliometric Analysis of the Explanatory Factors of the Air-Crashes in the World (1950-2008)". Journal of Transportation Safety \& Security, 5:165-185 https://doi.org/10.1080/19439962.2012.749968

Idrissi, A., LI Chu, M. 2005. "CSPAC: un modèle de résolution du problème d'allocation de capacités. MOSIM, Alexandre Vautier, Sylvie Saget. Majec STIC 2005 : Manifestation des Jeunes Chercheurs francophones dans les domaines des STI", Rennes, pp.172-179. 
International Civil Aviation Organization [ICAO] 2010. Environmental Report 2010, Aviation and Climate Change. Produced by the Environment Branch of the ICAO in collaboration with FCM Communications Inc, $260 \mathrm{p}$.

Janic, M. 2007. The Sustainability of Air Transportation. A Quantitative Analysis and Assessment. ISBN: 978-0-75464967-0, Ashgate eds, $374 \mathrm{p}$.

Michel, D., Prud'homme, R. 2007. Infrastructures de transport, mobilité et croissance. Rapport du conseil d'Analyse Economique. La Documentation française, Paris, 241p.
Raffarin, M. 2002. "Le contrôle aérien en France: congestion et mécanismes de prix". Thèse de Doctorat en Sciences Economiques de l'Université Paris 1- Panthéon Sorbonne.

Venkatakrishnan C.S., Barnet, A., Odoni, A.R. 1993. "Landings at Logan Airport: describing and increasing airport capacity". Transportation Science, 27(3):211-227. https://doi.org/10.1287/trsc.27.3.211

Varian, H.R., ed. 2011. Introduction à la microéconomie. Traduction de la $7 e$ édition américaine par Bernard Thiry, Collection: Ouvertures économiques, De Boeck Supérieur.

Received on 12-01-2017

Accepted on 02-02-2017

Published on 29-03-2017

DOI: https://doi.org/10.6000/1929-7092.2017.06.08

(C) 2017 Besma et al.; Licensee Lifescience Global.

This is an open access article licensed under the terms of the Creative Commons Attribution Non-Commercial License (http://creativecommons.org/licenses/by-nc/3.0/) which permits unrestricted, non-commercial use, distribution and reproduction in any medium, provided the work is properly cited. 